Caspersson, T., Nyström, C. \& Santesson, L. (1941). Naturwissenschaften, 29, 29.

— \& Santesson, L. (1942). Acta radiol., Stockh., Suppl. 46.

Claude, A. (1943a). Science, 97, 451. (1943b). Biol. Symp. 10, 111.

Davidson, J. N. \& Waymouth, C. $(1944 a)$. Biochem. J. 38, 39. (1944b). Biochem. J. 38, 375.

(1944c). Proc. Roy. Soc. Edin. 62 B, 96. (1944d). Nutr. Abstr. Rev. 14, 1.

Dickens, F. \& Weil-Malherbe, H. (1943). Cancer Res. 3, 73. Dische, Z. (1930). Mikrochemie, 8, 4.

Dumm, M. E. (1943). J. cell. comp. Physiol. 21, 27.

Fujiwara, T., Nakahara, W. \& Kishi, S. (1937). Gann, 31, 51.

Higgins, G. M. \& Anderson, R.M.(1931). Arch. Path.12, 186.

Hoerr, N. L. (1943). Biol. Symp. 10, 185.

Kerr, S. E. (1940). J. biol. Chem. $132,147$.

Kossel, A. (1882). Hoppe-Seyl. Z. 7, 7.

Kosterlitz, H. W. (1944a). Biochem. J. 38, Proc. xiv. (1944b). Nature, Lond., 154, 207.

—— \& Cramb, I. D. (1943). J. Physiol. 102, 18 P.
Lazarow, A. (1943). Biol. Symp. 10, 9.

Masing, E. (1911). Arch. exp. Path. Pharmak. 66, 71.

Mejbaum, W. (1939). Hoppe-Seyl. Z. 258, 117.

Norris, J. L., Blanchard, J. \& Povolny, C. (1942). Arch. Path. 34, 208.

Orr, J. W. (1940). J. Path. Bact. 50, 393.

Rapoport, S., Lever, E. \& Guest, G. M. (1943). J. biol. Chem. 149, 57.

Robertson, T. B. \& Dawbarn, M. C. (1929). A ust. J. exp. Biol. med. Sci. 6, 261.

Rondoni, P. (1941). Schweiz. med. Wschr. 71, 1354.

Rosenthal, O. \& Drabkin, D. L. (1943). J. biol. Chem. $150,131$.

Schlenk, F. (1942). J. biol. Chem. 146, 619.

Sevag, M. G., Smolens, J. \& Lackman, D. B. (1940). J. biol. Chem. 134, 523.

Sugiura, K. \& Rhoads, C. P. (1941). Cancer Res. $1,3$.

Sulkin, N. M. (1943). Anat. Rec. 73, 107.

Thomson, W. (1936). J. Hyg., Camb., 36, 24.

Tichmeneff, N. (1914). Biochem. Z. 59, 326.

\title{
The Determination of Thiocyanate in Blood Serum
}

\author{
By R. G. BOWLER, Clinical Laboratory and Medical Unit, The London Hospital
}

(Received 31 July 1944)

Body water is distributed in three main compartments, blood plasma, cell fluid and the fluid in the intercellular spaces (interstitial fluid). In order to study changes in the distribution of water between these compartments it is necessary to be able to measure their volumes accurately. Crandall \& Anderson (1934) have described a method for determining the volume of water available to thiocyanate. It has been inferred that this volume is equivalent to the interstitial fluid volume (Peters, 1942). Their method involves the injection of a known amount of sodium thiocyanate intravenously followed by the determination of its concentration in the blood serum after sufficient time has been allowed for its complete distribution.

The concentration of thiocyanate in the serum is determined by treating a trichloroacetic acid filtrate of serum with a solution of ferric nitrate; the orange colour which develops is measured colorimetrically. The standard is prepared by adding a known amount of thiocyanate to serum and treating it by the same process.

In this laboratory, attempts to follow changes in the volume of the interstitial fluid in cases of traumatic shock have met with little success. Determinations at intervals on the same patient gave inconsistent results. The technique of estimation was investigated, and it was found that when the colour was compared photoelectrically with that of an aqueous solution of NaSCN instead of a standard filtrate, recoveries were about $7.5 \%$ low. This was due to the trichloroacetic acid interfering with the colour development in the filtrate. Attempts to obviate this error by the use of different protein precipitants ( $p$-toluenesulphonic acid, uranyl nitrate, etc.) were unsuccessful; low recoveries were still obtained.

Conditions affecting the colour development were then studied. It was found that in Crandall \& Anderson's method the concentration of the reagent is far below the optimum. The use of a modified method gave quantitative recoveries which were unaffected by the trichloroacetic acid.

\section{EXPERIMENTAL}

Colorimeter. A tungsten filament source was used, infrared radiation being removed by a $2 \mathrm{~mm}$. thickness of Chance's 'Calorex' glass. The solution was measured in a $2 \mathrm{~cm}$. solution thickness. A blue filter was used, Ilford 'Spectrum Blue' no. 602, with a maximum transmission at $4700 \mathrm{~A}$.

Standard thiocyanate solution. When $500 \mathrm{mg}$. NaSCN have been injected into an average-sized man, the concentration of thiocyanate in the serum is about $3 \mathrm{mg}$. NaSCN/ $100 \mathrm{ml}$. A solution of NaSCN slightly stronger than $0.1 \mathrm{~N}$ was made by dissolving $11.5 \mathrm{~g}$. of the salt in water and diluting to $1 \mathrm{l}$. This was standardized by titration against $0 \cdot 1 \mathrm{~N}-\mathrm{AgNO}_{3}$. The concentration was then adjusted to be exactly 0.1 N-NaSCN, equivalent to $8.11 \mathrm{~g}$. NaSCN/1. By diluting $35.1 \mathrm{ml}$. of the $0.1 \mathrm{~N}$-solution to 11 ., and again diluting $35.1 \mathrm{ml}$. of this solution to $1 \mathrm{l}$., a concentration of 
$0.01 \mathrm{mg}$. $\mathrm{NaSCN} / \mathrm{ml}$. was obtained. $3 \mathrm{ml}$. of this solution contained about the same amount of $\mathrm{NaSCN}$ as there is in $1 \mathrm{ml}$. of serum.

The effect of ferric nitrate concentration on colour intensity. To a series of tubes, each containing $0.03 \mathrm{mg}$. NaSCN and $2.5 \mathrm{ml}$. $2 \mathrm{~N}-\mathrm{HNO}_{3}$, varying amounts of ferric nitrate were added. The volume was made up to $10 \mathrm{ml}$. A set of controls was similarly prepared, the thiocyanate solution being replaced by an equal volume of water. The amount of ferric nitrate added varied from $3 \mathrm{~g}$. to $0.05 \mathrm{mg}$., or 60,000 to 1 equivalents of the thiocyanate. The colour intensities of the solutions and controls were measured, soon after development, against distilled water. The extinction due to the thiocyanate was obtained by deducting that of the control from the solution. The results are shown in Fig. 1.

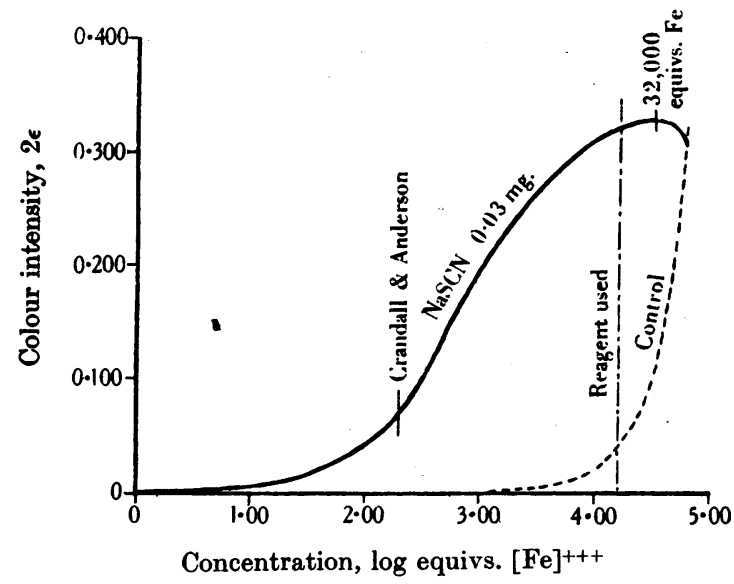

Fig. 1. Effect of ferric nitrate concentration on the colour intensity of the thiocyanate-ferric nitrate complex.

It is seen that a very large excess of ferric nitrate was required to produce maximum colour. In this high concentration, partial hydrolysis caused a large increase in the blank colour. For optimum conditions it is necessary to use a concentration which, whilst giving the maximum colour intensity for the thiocyanate, will have a small blank value; $0 \cdot 8 \mathrm{~g}$. $(16,000$ equivalents) is suitable. The amount of thiocyanate used in this experiment was twice that which will usually be present in a serum filtrate. The ratio, which will be in the optimum range, will therefore be of the order of 32,000 equivalents of $[\mathrm{Fe}]^{+++}$to 1 equivalent of $[\mathrm{SCN}]^{-}$. Interfering substances should then have a minimum effect on the colour development.

The effect of acid concentration on the colour intensity. A series of tubes was prepared each containing $0.03 \mathrm{mg}$. $\mathrm{NaSCN}, 1.5 \mathrm{~g}$. ferric nitrate $(30,000$ equivalents) and varying amounts of a standardized solution of nitric acid. The volume was made up to $10 \mathrm{ml}$. in each case. The final concentration of acid ranged from 0 to $1 \cdot 13 \mathrm{~N}$. Control samples were also prepared, differing only in that they contained no thiocyanate. The colour intensities of the solutions and controls were measured against distilled water. The extinction due to the thiocyanate was obtained by deducting the control value. The results are shown in Fig. 2.

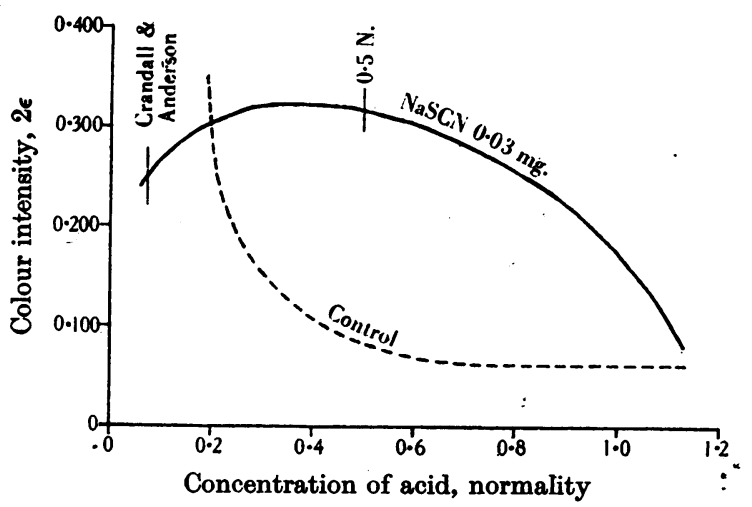

Fig. 2. Effect of acid concentration on the colour intensity of the thiocyanate-ferric nitrate complex.

Maximum colour was developed in $0.35 \mathrm{~N}$-acid, but the blank value was high, because of hydrolysis of the ferric nitrate. In $0.5 \mathrm{~N}$-acid the blank was reasonably low and the colour intensity due to thiocyanate was still nearly maximal.

Stability of the coloured complex. Solutions were prepared containing $0.03 \mathrm{mg}$. NaSCN in $5 \mathrm{ml}$. of water; $0.8 \mathrm{~g}$. ferric nitrate in $5 \mathrm{ml}$. of $\mathrm{N}-\mathrm{HNO}_{3}$ was added in artificial light, and the colour intensity measured at once against controls. The solutions were then allowed to stand in different light intensities, some in a dark cupboard, others in electric light (about $4 \mathrm{ft}$. below a $60 \mathrm{~W}$. lamp), the remainder in dull daylight. Measurements were made at intervals. Results are shown in Fig. 3.

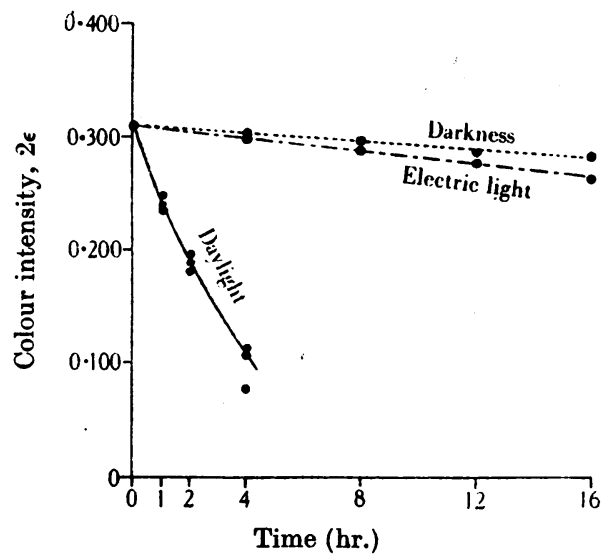

Fig. 3. Stability of the coloured complex of thiocyanate with ferric nitrate.

Exposure of the coloured solutions to light caused them to fade. There was a decrease in the colour intensity of about $20 \% / \mathrm{hr}$. in daylight, $1 \% / \mathrm{hr}$. in artificial light and $0.5 \% / \mathrm{hr}$. when kept in the dark. up to $16 \mathrm{hr}$. 
The reagent should be added in artificial light and the colour intensity measured within $15 \mathrm{~min}$. There will then be no appreciable error due to fading.

\section{Summary of the conditions necessary for optimum colour development}

(1) Ferric nitrate should be present in large excess, in the ratio of at least $27,000 / 1 \mathrm{~g}$., or $16,000 / 1$ equivalent, $\mathrm{Fe}\left(\mathrm{NO}_{3}\right)_{3} \cdot 9 \mathrm{H}_{2} \mathrm{O} / \mathrm{NaSCN}$.

(2) The final solution should be $0.5 \mathrm{~N}-\mathrm{HNO}_{3}$.

(3) Exposure of the coloured solution to daylight must be.carefully avoided.

(4) The colour intensity should be measured within $15 \mathrm{~min}$. after the addition of the reagent.

\section{THE ESTIMATION OF THIOCYANATES IN BLOOD SERUM}

\section{Reagents Method}

Trichloroacetic acid solution. $20 \mathrm{~g}$. trichloroacetic acid are dissolved in $100 \mathrm{ml}$. of watér and filtered.

Ferric nitrate-nitric acid reagent. $80 \mathrm{~g} . \mathrm{Fe}\left(\mathrm{NO}_{3}\right)_{3}, 9 \mathrm{H}_{2} \mathrm{O}$ are dissolved in $250 \mathrm{ml}$. $2 \mathrm{~N}-\mathrm{HNO}_{8}$, made to $500 \mathrm{ml}$. with water and filtered.

\section{Estimation}

Oxalated or citrated plasma must not be used because of the colour which the anticoagulant produces with ferric nitrate.

$1 \mathrm{ml}$. of serum is measured into a test-tube, $6.5 \mathrm{ml}$. water and $2.5 \mathrm{ml}$. trichloroacetic acid solution added, mixed by inversion several times, allowed to stand for about $10 \mathrm{~min}$. and filtered through a Whatman no. 40 paper $9 \mathrm{~cm}$. diameter. $5 \mathrm{ml}$. of the filtrate are treated with $5 \mathrm{ml}$. of the ferric nitrate reagent in absence of daylight, mixed and measured within $15 \mathrm{~min}$. against the control.

$1 \mathrm{ml}$. of a sample of serum withdrawn before injection of thiocyanate is taken through the same process for a control.

\section{Standard curve Results}

Various amounts of the standard thiocyanate solution were diluted to $5 \mathrm{ml}$. with water, $5 \mathrm{ml}$. of the ferric nitrate reagent added, and the colour intensity measured against a control of $5 \mathrm{ml}$. reagent diluted with $5 \mathrm{ml}$. of water.

It is seen from Table 1 that the Beer-Lambert law is obeyed. The colour produced is about $50 \%$ greater than that given by Crandall \& Anderson's method.

Table 1. Proportionality of colour produced by thiocyanate and ferric nitrate

$\begin{array}{cc}\text { NaSCN } & \begin{array}{c}\text { Colour intensity } \\ \text { (mg.) }\end{array} \\ 0.030 & 0.312 \\ 0.025 & 0.263 \\ 0.020 & 0.209 \\ 0.015 & 0.157 \\ 0.010 & 0.105 \\ 0.005 & 0.053\end{array}$

Biochem. 1944, 38

\section{Recoveries}

Known amounts of the standard solution of thiocyanate were added to normal sera; they were then estimated as described above and the colour in: tensity compared with the standard curve. In a series of 25 sera the mean recovery was $100 \%$, the maximum deviation from the mean $3 \%$, and the standard deviation $\mathbf{0} \cdot 8$. Under these conditions the trichloroacetic acid does not interfere with the colour development.

\section{Nature of the coloured complex}

Considerable use has been made of the reaction between ferric salts and thiocyanates in the colorimetric determination of small amounts of iron (Snell \& Snell, 1936). According to Schlesinger \& Van Valkenburgh (1931), the colour in aqueous solution is due to the ion $\left[\mathrm{Fe}(\mathrm{CNS})_{6}\right]^{m}$ when there is an excess of thiocyanate present. In the determination of thiocyanate by the addition of a large excess of ferric salt, as described in this paper, the coloured complex appears to be different in nature. A complete study of these unstable complexes could not be undertaken at the time, but it is of interest to note the results of some preliminary investigations.

On shaking the aqueous solution with a non-polar solvent like ether or benzene, the complex formed when thiocyanate was in excess was completely extracted from the aqueous phase. The complex formed when a large excess of iron was present was insoluble in the non-polar solvent. This suggests that the first substance is weakly ionized and the second strongly ionized in aqueous solution.

Electrophoresis of the aqueous solution caused the brown colour to move towards the cathode when an excess of iron was present. Schlesinger \& Van Valkenburgh (1931) found that the excess-thiocyanate complex migrated towards the anode. It would appear that the colour is associated with the positive ion in the first case and with the negative ion in the latter.

Absorption curves in the visual region, measured with a Hilger-Nutting spectrophotometer, showed that in both cases the maximum absorption is in the violet. A peak was observed at about $4550 \mathrm{~A}$ when the excess iron complex was examined. A satisfactory curve was not obtained when excess thiocyanate was used, owing to rapid fading. Further investigation is necessary before the nature of the complex can be found.

\section{SUMMARY}

1. Conditions affecting the colorimetric determination of small amounts of thiocyanate in blood serum by the ferric thiocyanate reaction have been studied. 
2. Trichloroacetic acid used for the removal of protein may interfere with colour development when Crandall \& Anderson's method is used.

3. By increasing the concentrations of ferric nitrate and nitric acid in the reagent to optimum conditions, quantitative results were obtained.

4. A photoelectric method for the determination of thiocyanate in blood serum which gives accurate results is described.

I wish to thank Dr A. C: Crooke and Dr C. J. O. R. Morris for encouragement and advice. The expenses of this research were defrayed from the Yarrow Fund of the London Hospital.

\title{
REFERENCES
}

Crandall, L. A., Jr. \& Anderson, M. X. (1934). Amer. J. Schlesinger, H. L. \& Van Valkenburgh, H. B. (1931). digest. Dis. Nutr. $1,126$.

Peters, J. P. (1942). Ann. Rev. Physiol. 4, 93.

J. Amer. chem. Soc. 53, 1212.

Snell, F. D. \& Snell, C. T. (1936). Colorimetric Methods of

Analysis. New York: D. Van Nostrand Co. Inc.

\section{A New Method for the Oxidation of Aneurin to Thiochrome and. a Procedure for the Determination of Aneurin in Oats}

\author{
By W. I. M. HOLMAN, The Rowett Institute, Aberdeen
}

(Received 28 July 1944)

It was desired as part of an investigation on the composition of oats to determine the aneurin content of a large number of samples with sufficient accuracy to distinguish relatively small differences. The methods of Hennessy \& Cerecedo (1939) and Harris \& Wang (1941) did not give in our hands the required degree of precision. The method of Nicholls, Booth, Kent-Jones, Amos \& Ward (1942) for flour is not applicable to oats since the sample is not digested with a proteolytic enzyme before extraction and only free aneurin is determined. It was considered advisable to study in some detail the oxidation of aneurin to thiochrome, the extraction of aneurin from oats and the purification of extracts by the use of a selective adsorbent.

Existing methods for the determination of aneurin by oxidation to thiochrome are modifications of the method of Jansen (1936). Various workers have drawn attention to factors likely to lead to error in the application of this method, viz. ferricyanide concentration (Nicholls et al. 1942); partition between aqueous and isobutanol layers (Herd, Mundy \& Ridyard, 1943); instability of isobutanol solutions of thiochrome in ultra-violet (u.v.) light (Nicholls et al. 1942; Wokes, Organ, Still \& Jacoby, 1944).

\section{EXPERIMENTAL}

\section{Oxidation of aneurin to thiochrome}

In a search for an oxidizing agent weaker than ferricyanide, which might render the oxidation less difficult to control and the extraction with isobutanol unnecessary, a number of metal oxides used as oxygen electrodes was examined. Such oxides provide a small but constant partial pressure of oxygen. Heating an alkaline solution of aneurin with $\mathrm{HgO}$ for $10 \mathrm{~min}$. at $100^{\circ}$ was found to be the most promising, but the presence of solid $\mathrm{HgO}$ caused erratic results, apparently because of adsorption of thiochrome on the $\mathrm{HgO}$. A saturated solution of $\mathrm{HgO}$ in $25 \%(\mathrm{w} / \mathrm{v}) \mathrm{KCl}$ solution which is alkaline in reaction gave not only reproducible results but also a much greater yield of thiochrome, as indicated by the intensity of its fluorescence after heating for $10 \mathrm{~min}$. at $100^{\circ}$.

A more satisfactory method of preparing such a solution is by mixing solutions of $\mathrm{HgCl}_{2}, \mathrm{KCl}$ (or $\mathrm{NaCl}$ ) and $\mathrm{KOH}$ (or $\mathrm{NaOH}$ ):

$$
\mathrm{HgCl}_{2}+2 \mathrm{KOH} \rightleftharpoons \mathrm{HgO}+2 \mathrm{KCl}+\mathrm{H}_{2} \mathrm{O} .
$$

Precipitation of mercuric oxychloride does not occur if the proportion of $\mathrm{HgCl}_{2}$ is sufficiently small. When $5 \mathrm{ml}$. of $25 \%$ (w/v) $\mathrm{KCl}$ solution were used the maximum amount of $1 \% \mathrm{HgCl}_{2}$ solution which could be added without risk of precipitation of mercuric oxychloride when the solution was subsequently made alkaline was found to be $1 \mathrm{ml}$. To $5 \mathrm{ml}$. of a freshly prepared solution of aneurin in $25 \% \mathrm{KCl}$ was added $1 \mathrm{ml}$. of $1 \% \mathrm{HgCl}_{2}$ solution followed by $4 \mathrm{mi}$. of $\mathrm{NaOH}$ solution. A fluorescence developed which, when the solution was heated, soon reached its maximum intensity. The rate of development increased as the temperature was raised, but destruction of thiochrome occurred at high temperatures. At $40^{\circ}$, the most suitable temperature, the fluorescence reached its maximum intensity in $15 \mathrm{~min}$., and destruction did not occur on further heating. The concentration of alkali used affected the development of the fluorescence slightly, but the temperature of the solution when the alkali was added had a greater effect. The maxi- 